\title{
Sol-gel derived porous ultra-high temperature ceramics
}

\author{
Fei LI $^{a,{ }^{*}}$, Xiao HUANG ${ }^{b}$, Ji-Xuan LIU ${ }^{a}$, Guo-Jun ZHANG ${ }^{a, *}$ \\ ${ }^{a}$ State Key Laboratory for Modification of Chemical Fibers and Polymer Materials, Institute of Functional \\ Materials, Donghua University, Shanghai 201620, China \\ ${ }^{b}$ Institute for the Conservation of Cultural Heritage, Shanghai University, Shanghai 200444, China
}

Received: December 20, 2018; Revised: April 10, 2019; Accepted: April 15, 2019

(C) The Author(s) 2019.

\begin{abstract}
Ultra-high temperature ceramics (UHTCs) are considered as a family of nonmetallic and inorganic materials that have melting point over $3000{ }^{\circ} \mathrm{C}$. Chemically, nearly all UHTCs are borides, carbides, and nitrides of early transition metals (e.g., Zr, Hf, Nb, Ta). Within the last two decades, except for the great achievements in the densification, microstructure tailoring, and mechanical property improvements of UHTCs, many methods have been established for the preparation of porous UHTCs, aiming to develop high-temperature resistant, sintering resistant, and lightweight materials that will withstand temperatures as high as $2000{ }^{\circ} \mathrm{C}$ for long periods of time. Amongst the synthesis methods for porous UHTCs, sol-gel methods enable the preparation of porous UHTCs with pore sizes from 1 to $500 \mu \mathrm{m}$ and porosity within the range of $60 \%-95 \%$ at relatively low temperature. In this article, we review the currently available sol-gel methods for the preparation of porous UHTCs. Templating, foaming, and solvent evaporation methods are described and compared in terms of processing-microstructure relations. The properties and high temperature resistance of sol-gel derived porous UHTCs are discussed. Finally, directions to future investigations on the processing and applications of porous UHTCs are proposed.
\end{abstract}

Keywords: sol-gel; ultra-high temperature ceramics; porous ceramics; processing; microstructure

\section{Introduction}

Ultra-high temperature ceramics (UHTCs) are a class of nonmetallic and inorganic materials that have melting point over $3000{ }^{\circ} \mathrm{C}$ and are typically borides, carbides, and nitrides of early transition metals (e.g., Zr, $\mathrm{Hf}, \mathrm{Nb}, \mathrm{Ta})[1-8]$. Due to the combination of series of excellent physical and chemical properties, such as high hardness, good high-temperature stability, and

*Corresponding authors.

E-mail: F. Li, lifei80380@163.com;

G. Zhang, gjzhang@dhu.edu.cn excellent solid-phase stability, UHTCs are considered as promising candidate materials for high-temperature structural applications, including engines, hypersonic vehicles, plasma arc electrode, cutting tools, furnace elements, and high-temperature shielding [7,9-13]. UHTCs are difficult to densify without sintering additives and external pressure. Numerous researches have been made in recent decades for the synthesis and densification of UHTCs at moderate conditions and further enhancements of their performance [14]. One of the potential applications for porous UHTCs is used as thermal insulating materials in thermal protection systems of reusable launch vehicles, which experience extreme high temperatures $\left(>2000{ }^{\circ} \mathrm{C}\right)$ during high- 
speed cruise. Few materials can meet this criterion. The maximum using temperature for typical rigid tiles (e.g., alumina-enhanced thermal barrier, AETB) is $\sim 1600{ }^{\circ} \mathrm{C}$ [15]. Recent interest in UHTCs has been motivated by the search for materials that can withstand extreme environments over $2000{ }^{\circ} \mathrm{C}$. UHTCs possess excellent phase stability at high temperatures. Hopefully, pores are introduced in UHTCs to give out novel and lightweight thermal insulating materials.

Many researchers focused on the preparation of porous UHTCs, aiming to develop high-temperature resistant, sintering resistant, and lightweight materials [16-23]. In the late 1990s, NASA and Aspen Systems proposed a Phase I project to develop ultra-high temperature resistant zirconium and hafnium carbide aerogels. They would use their expertise in aerogel manufacturing and sol-gel science to develop a lowtemperature process for the production of refractory carbide aerogels. However, no further open reports or publications can be reached. In March 2013, Prof. Franks and Dr. Tallon from the University of Melbourne started a two-and-a-half-year project on "multi-scale porous ultra-high temperature ceramics" funded by the Asian Office of Aerospace Research and Development (AOARD) [16]. The object of this project was to develop highly porous UHTCs that can be potentially used in insulation packages for ultra-high temperature applications. Processing conditions were investigated and then optimized to prepare zirconium diboride porous materials with up to $92 \%$ porosity by replica, particle stabilized foams, ice templating, and partial sintering methods. In August 2016, Prof. Ireland from University of Oxford and partners from University of Birmingham, Imperial College London, and University of Southampton started a five-year project entitled "transpiration cooling systems for jet engine turbines and hypersonic flight" funded by Engineering and Physical Sciences Research Council (EPSRC) [24]. One of their research topics was to develop UHTCs (zirconium diboride) with controlled porosity to be used as a key component in transpiration cooling systems for hypersonic flights. In January 2017, Dr. Li from Donghua University started a three-year project funded by National Natural Science Foundation of China (NSFC) to develop porous zirconium carbide foams by direct foaming methods [22]. However, very limited papers on the preparation and application of porous UHTCs can be found [17,18,21-23,25-27].

The processing routes used for the production of porous ceramics can be categorized as partial sintering, replica method, sacrificial template method, and direct foaming method [28-32]. It is important to get a well dispersed ceramic slurry or liquid precursor for the fabrication of porous ceramics with tailored microstructure and chemical composition [33-35]. Porous UHTCs can be obtained by using ceramic powders as raw materials, followed by colloidal processing (e.g., freeze casting, gel casting, and foaming) of the ceramic slurry, shaping, and pressureless sintering [17,18,27]. The sintering temperature $\left(1800-2100{ }^{\circ} \mathrm{C}\right)$ is selected to allow for particle necking to provide good mechanical strength, but not high enough to get full densification of the particles in the skeletons [16]. These powder-derived porous UHTCs are not sintering-resistant. At higher temperatures, grain coarsening leads to the formation of large grains, indicating poor high-temperature stability [36]. Large grains often result in a degradation in strength.

An alternative way to prepare porous UHTCs is to use the liquid sols which contain transition metal salts, boron source, and organic carbon source as raw materials [21-23,25]. After sol-gel reactions, shaping with specific techniques, drying at moderate conditions, and pyrolysis at high temperatures, the porous UHTCs with desired compositions are obtained. Numbers of papers focus on the design and pyrolysis of UHTCs precursors to fine UHTCs powders through sol-gel methods [37]. However, rare works have been published on sol-gel derived porous monolithic UHTCs. These porous UHTCs are expected as thermal resistant materials at extreme high temperatures, and also should be able to bear loadings in some cases. Evaluation of the porous UHTCs should be based on high-temperature stability (e.g., dimensional, microstructure, thermal expansion), mechanical property, thermal conductivity, and thermal shock resistance, etc.

Some excellent reviews and papers concerning the sol-gel derived porous monoliths are available [29,38, 39]. However, few papers focusing on the preparation of non-siliceous especially UHTCs monoliths from sol-gel methods can be found. The aim of this article is to summarize and compare some of the sol-gel processing routes currently available for the preparation of porous monolithic UHTCs, including porous $\mathrm{ZrC}$-, HfC-, and $\mathrm{ZrB}_{2}$-based ceramics. The synthesis of UHTCs powders from sol-gel or liquid precursor routes will not be discussed here. Sacks et al. [40], Dollé et al. [41], Yan et al. [42], Ang et al. [43], Cai et al. [44], and 
Li et al. [37] are suggested for those interested in these research topics.

\section{Processing-microstructure relations}

\section{1 General features of porous UHTCs via sol-gel process}

Sol-gel is a very powerful technique for the synthesis of wide range materials $[29,38,45,46]$. It is generally involved with the mixing of chemicals in a solution, gelation, drying, and post-treatment to obtain final products [29]. Starting from a homogeneous liquid state, nanopowders, fibers, films, and porous monoliths with tailored structure can be made from sol-gel routes combined with various drying and shaping techniques. Beginning a synthesis in the liquid state, in which all starting reagents are mixed at molecular level, can also result in lower synthesis temperatures [43,47]. A large variety of parameters, such as the choice of the precursors, its concentration, temperature, solvent, etc., have significant influence on the composition, microstructure, and properties of the sol-gel derived materials $[29,38]$. Heat treatment is important for drying gels as well as the converting organic/inorganic hybrid gels to ceramics [48]. Drying of the gels during which the solvent between gel network is removed by evaporation or sublimation is a critical step in synthesizing monoliths. Shrinking, cracking, and collapse of the gels caused by surface tension are very common in sol-gel processing, which make it often difficult to prepare large monolithic materials $[29,48]$. Powders and cracked fragments are often obtained in sol-gel processing of UHTCs, as shown in Fig. $1[41,49]$. Special drying techniques such as supercritical drying and freeze drying, as well as other strategies like surface modification, exhausted solvent-exchange or combinations of these techniques have been developed to weaken the capillary forces during drying to obtain monolithic pieces [29,45,50-52].

In the case of sol-gel processing of porous UHTCs, the preparation methods can roughly be divided in three categories according to how the porous structures are formed in the green body: templating method, foaming method, solvent evaporation method, as schematically illustrated in Fig. 2. The templating method involves the impregnation and infiltration of a porous structure (as template) with the preceramic sol $[49,53]$. After the impregnation and infiltration process, the green body is first dried and then heated at temperatures up to $1600{ }^{\circ} \mathrm{C}$ for the formation of porous UHTCs via carbothermal reduction reaction. The porous UHTCs exhibit almost the same morphology as the original porous template but with some extent of shrinkage. The use of porous structure as template is an

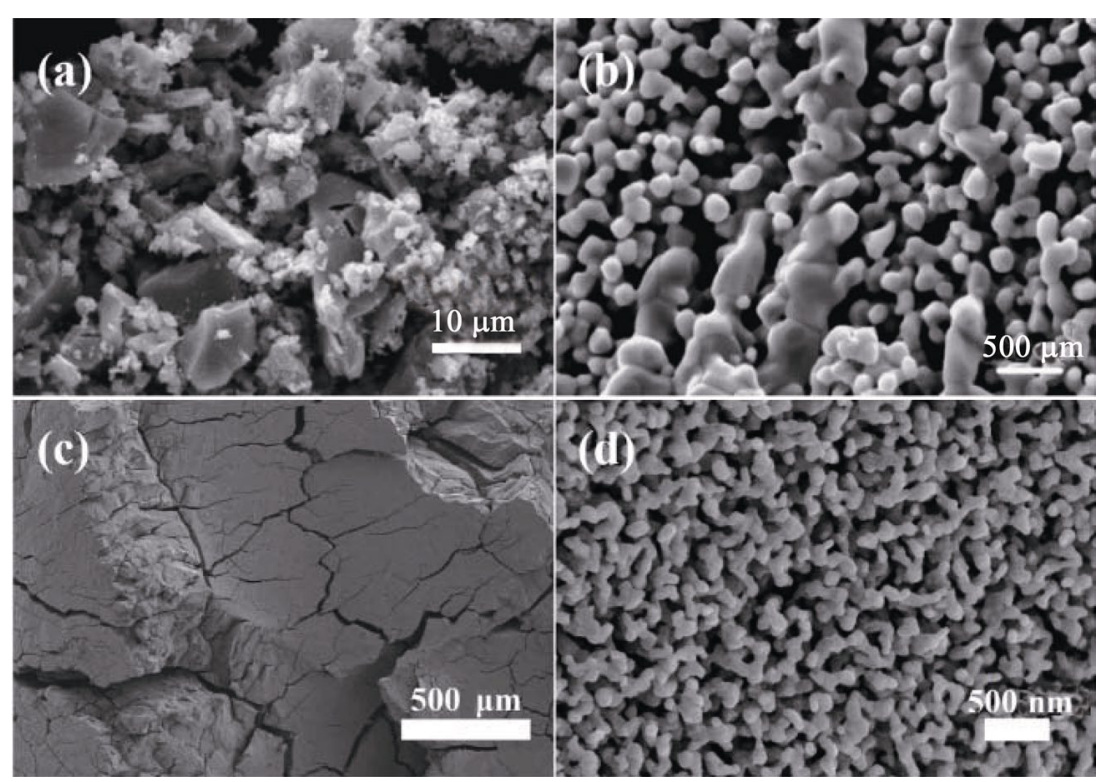

Fig. 1 SEM images of sol-gel derived $\mathrm{ZrC}$ powders heated (a) at $1600{ }^{\circ} \mathrm{C}$ for $3 \mathrm{~h}$ and (b) at $1400{ }^{\circ} \mathrm{C}$ for $2.5 \mathrm{~h}$ then at $1800{ }^{\circ} \mathrm{C}$ for 6 min. Reproduced with permission from Ref. [41], (C) Elsevier Ltd. 2006. (c) Low and (b) high magnification SEM images of sol-gel derived $\mathrm{ZrC} / \mathrm{SiC}$ composite heated at $1500{ }^{\circ} \mathrm{C}$ for $1 \mathrm{~h}$ [49]. Reproduced with permission from Ref. [49], (C) Springer Science+Business Media, LLC, part of Springer Nature 2018. 
(I)

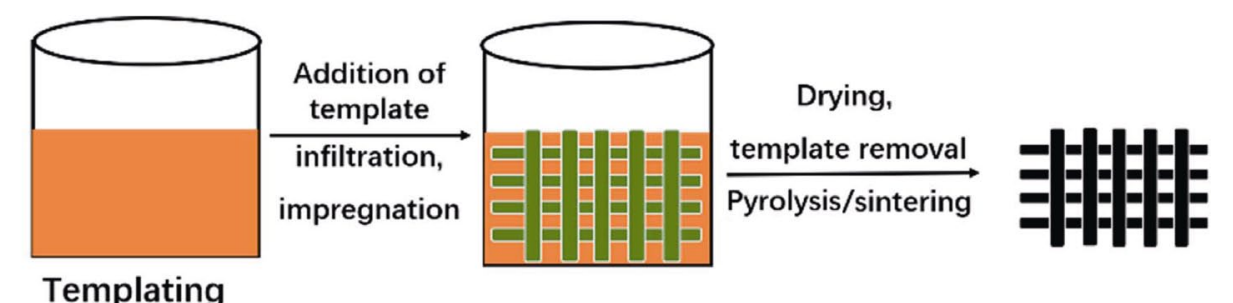

(Template)

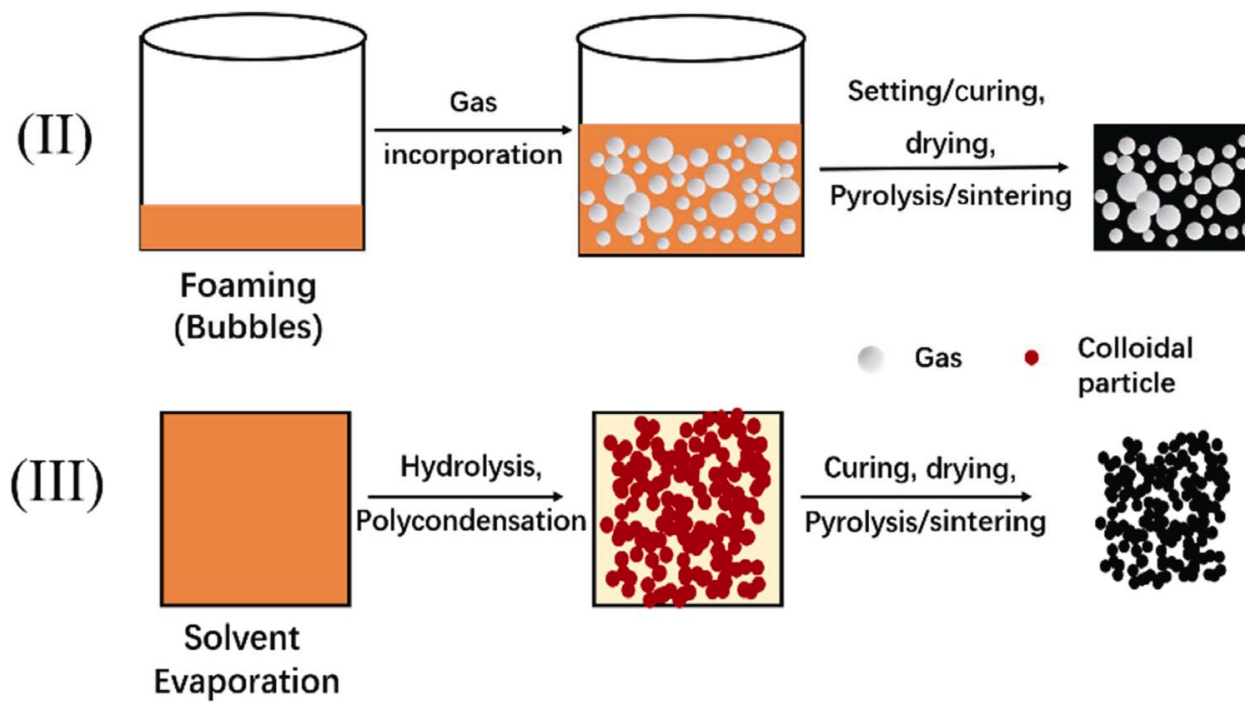

Fig. 2 Scheme of sol-gel methods for the preparation of porous UHTCs.

important feature for this method. In the foaming methods, bubbles are first generated by introducing air or volatile reagents into the preceramic sol, then are set to obtain foamed green body $[23,25]$. The foamed green body is afterwards heated at high temperatures to obtain porous UHTCs. Bubble generation and stabilization are the characteristic features of this foaming method. In solvent evaporation methods, which is template free, the preceramic sol undergoes sol-gel transition to form a monolithic wet gel, which contains a continuous solid network enclosing a continuous liquid phase [21,22]. The solvent between the solid network evaporates out by heat treatment and pores are left behind in the organic/inorganic hybrid gels. Consequently, the porous hybrid gels are pyrolyzed at high temperatures to obtain porous UHTCs. No porous templates are used and no bubbles are generated in this solvent evaporation method.

In sol-gel derived porous UHTCs, which started from liquid precursors, heat treatment at temperatures up to $1300-1600{ }^{\circ} \mathrm{C}$ in inert atmosphere was necessarily required to convert the preceramic gels into UHTCs composition [41,54-56]. Figure 3 shows the typical TG-DSC curves of the dried gel in inert gas flow at 40 to $1600{ }^{\circ} \mathrm{C}$ and the XRD patterns of the pyrolyzed products at various temperatures [21]. These results demonstrated that the UHTCs phases started to form at $1200{ }^{\circ} \mathrm{C}$ and completed at temperatures from 1300 to $1500{ }^{\circ} \mathrm{C}$ accompanied by a huge weight loss.

$\mathrm{A}$ number of porosities and pore sizes have been produced by these methods for $\mathrm{ZrC}, \mathrm{ZrC} / \mathrm{SiC}, \mathrm{ZrB}_{2}$, and $\mathrm{ZrB}_{2} / \mathrm{SiC}$, etc. [21-23,25,53,57]. Figure 4 is a map of porosities-pore sizes-applications of several groups of porous materials [30]. And the locations of the sol-gel derived porous UHTCs are also shown in Fig. 4. The pore sizes of the sol-gel derived porous UHTCs are relatively small when compared with the porous materials with similar porosity level. Such features demonstrate that the sol-gel derived porous UHTCs may find applications as high temperature resistant thermal insulators.

Table 1 lists the characteristics of the porous UHTCs made from various processing methods. All these processing methods can be used to prepare porous UHTCs with porosities over $70 \%$. Templating methods are simple and easy to handle with, and can be used to prepare porous UHTCs that mimicking templates. Foaming methods are suitable for the synthesis 

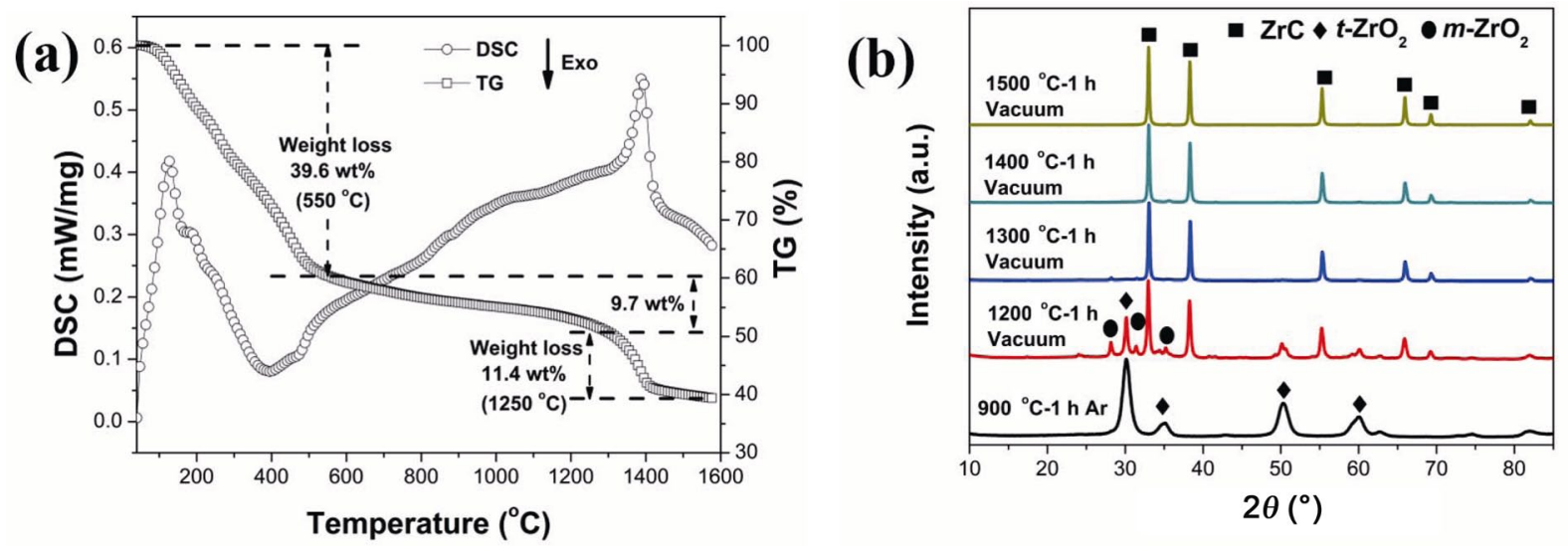

Fig. 3 (a) Typical TG-DSC curves of the dried gel in argon flow [21]. Reproduced with permission from Ref. [21], (C) Elsevier Ltd. 2018. (b) XRD patterns of the products obtained from pyrolyzing the dried gels at various temperatures [21]. Reproduced with permission from Ref. [21], (C) Elsevier Ltd. 2018.

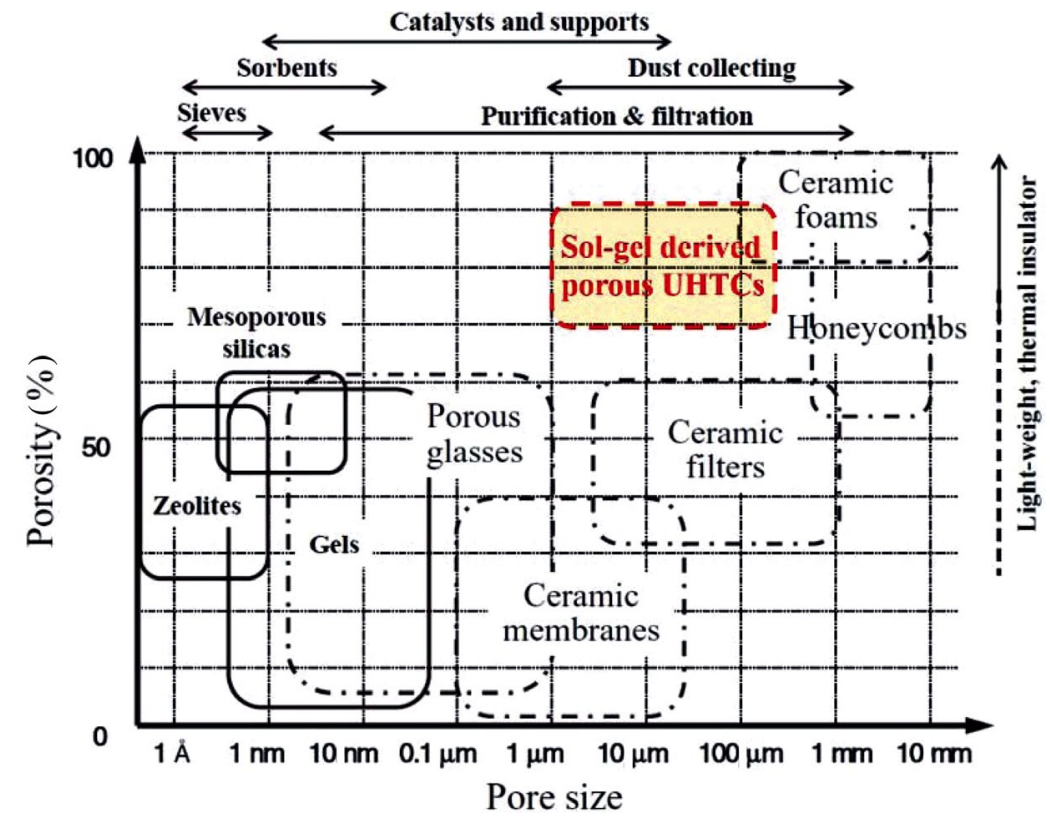

Fig. 4 Pore size and porosity of typical porous substances and ceramics [30]. Reproduced with permission from Ref. [30], (C) National Institute for Materials Science 2011.

Table 1 Characteristics of the porous UHTCs made from various processing methods

\begin{tabular}{cccccc}
\hline Composition & Method & Porosity & Pore size $(\mu \mathrm{m})$ & Type of the pores & $\begin{array}{c}\text { Compressive } \\
\text { strength (MPa) }\end{array}$ \\
\hline $\mathrm{ZrC} / \mathrm{C}[53]$ & Sol-gel, templating & $78 \%$ & $\sim 20$ & Open & - \\
$\mathrm{ZrC} / \mathrm{SiC}[49]$ & Sol-gel, templating & $78.1 \%$ & $80-200$ & Open & $0.4-0.67$ \\
$\mathrm{ZrC} / \mathrm{C}[23]$ & Sol-gel, foaming & $85 \%$ & $\sim 40$ & Closed cell & 0.4 \\
$\mathrm{ZrC}[25]$ & Sol-gel, foaming & $67.6 \%-93 \%$ & $100-300$ & Open \& closed & 0.15 \\
$\mathrm{ZrB} / \mathrm{ZrC} / \mathrm{SiC}[22]$ & Sol-gel, solvent evaporation & $74.3 \%-82 \%$ & $1.0-10$ & Open & $1.2-1.9$ \\
$\mathrm{ZrC} / \mathrm{SiC}[21]$ & Sol-gel, solvent evaporation & $\sim 70 \%$ & $3-16$ & Open & $0.3-0.7$ \\
$\mathrm{ZrB} / \mathrm{SiC}[17]$ & Camphene-based freeze casting & $10 \%-60 \%$ & $200-300$ & Open & $173-364$ \\
$\mathrm{ZrB} 2[18]$ & Ice templating & $48 \%-57 \%$ & $20-180$ & Layered structure & $18-68$ \\
$\mathrm{ZrB}$ & Gel casting & $55 \%$ & $\sim 220$ & Open & 79 \\
$\mathrm{ZrB}_{2} / \mathrm{SiC}[58]$ & Partial sintering & $2 \%-35 \%$ & $1.4-5.5$ & Open & - \\
\hline
\end{tabular}


of porous UHTCs with tailored open and closed cell structures. Solvent evaporation methods are suitable for the synthesis of porous UHTCs with pore sizes down to $1-20 \mu \mathrm{m}$ and with relatively high compressive strength. Porous UHTCs made by sol-gel methods possess high porosity and small pore size but with low compressive strength. Porous UHTCs made by gel casting, freeze casting, and partial sintering are strong but with relatively low porosities. Such statements are added in the revised manuscript.

\section{2 Templating methods}

Since invented by Schwartzwalder et al. [59] in 1963, templating methods have been simple and versatile ways to prepare porous ceramic products by using the natural or synthetic templates as skeletal supporting structure [31]. The great flexibility of the templating method is partly due to the fact that it is applicable to any ceramic material that can be appropriately dispersed into a slurry or a sol. The microstructures of template-derived porous ceramics depend primarily on the porous structure of the templates. However, there are only a few reports about the synthesis of cellular zirconium carbide and its composite in current literature. Rambo et al. [53] used wood templating method to prepare porous $\mathrm{ZrC} / \mathrm{C}$ ceramics with porosity of $78 \%$. The zirconia sol or colloidal suspension was prepared by hydrolysis and condensation of zirconium $n$-propoxide. Zirconia sol was vacuum infiltrated into the pine wood derived carbon template and was subsequently dried to obtain a zirconia gel coated porous wood structure. The infiltration and drying processes were carried out four times to reach a high zirconia content. Zirconia gel was converted into $\mathrm{ZrO}_{2}$ and then reacted with the wood derived carbon template to form $\mathrm{ZrC}$ phase upon pyrolysis. The original pine char microstructure was reproduced in the porous $\mathrm{ZrC} / \mathrm{C}$ ceramic. Island-like $\mathrm{ZrC}$ particles were observed on the cell walls and in the channels, as shown in Fig. 5.

In the wood derived porous UHTCs, in which the wood derived carbon templates also play the role as carbon source, it is difficult to produce near stoichiometric porous structures [53]. High residual carbon yield in the final ceramic composition seems to be characteristic feature for this wood templating method. The maximum achievable $\mathrm{ZrC}$ phase content was lower than 20 vol\% in Ref. [53]. The initial porosity of the biocarbon template and the amount of infiltrated preceramic precursor are crucial for the conversion ratio of metal oxide to metal carbide. The sol viscosity also plays a key role in the templating method [31,53]. Started from high viscosity sol, a nonhomogeneity of the sol-infiltration and the clogging of


Fig. 5 SEM images of the pine wood char with (a) low and (b) high magnifications. SEM images of the wood derived porous $\mathrm{ZrC/C}$ with (c) low and (d) high magnifications [53]. Reproduced with permission from Ref. [53], (c) Elsevier Ltd. 2005. 
the pores after multiple infiltration and drying cycles result in low ceramic content and inhomogeneous structures in the final porous products.

The low viscosity sol facilitates the entrance to the porous structures much more easily, and may allow higher weight gain during the cycling infiltration. Wood derived carbon templates are rigid and do not suffer from distortion or deformation during infiltration and drying processes; however, soft or flexible templates (e.g., polymeric sponge, melamine foam) do. $\mathrm{Li}$ et al. [49] reported the preparation of $\mathrm{ZrC} / \mathrm{SiC}$ foam by using melamine foam as template. They infiltrated furfuryl alcohol/polyzirconoxane/tetraethyl orthosilicate (FA/PZO/TEOS) derived hybrid sols into melamine foam to get a hybrid foam. The hybrid sol can be converted into the desired ceramic composition upon drying and pyrolysis with no extra carbon source is required. When impregnated with high viscosity sol, the as-dried hybrid foam showed twisted sides probably caused by the inhomogeneous sol infiltration and gel shrinkage, as shown in Figs. 6(a) and 6(b). The hybrid foam underwent nearly $10 \%$ linear shrinkage accompanied by gel shrinkage during drying. While treated with low viscosity hybrid sol, the original rectangular shape of the melamine foam was well retained, as shown in Fig. 6(c). These hybrid foams were converted into open-cell structured $\mathrm{ZrC} / \mathrm{SiC}$ foams after heat treatment at $1500{ }^{\circ} \mathrm{C}$ (Figs. 6(d) and 6(e)). The porous $\mathrm{ZrC} / \mathrm{SiC}$ obtained with the melamine template method can reach open porosity of $78.1 \%$ and possess a monomodal pore size distribution between 80 and $200 \mu \mathrm{m}$.

\section{3 Foaming methods}

Bubble stabilization in the wet foam is the critical issue in foaming methods, and plays a key role in controlling the porous structures of the final ceramic products [31,60-62]. Bubbles can be generated by introducing air or volatile reagents into a colloidal suspension or viscous liquid via strong mechanical mixing. The wet bubbles can be stabilized by rapid crosslinking/ gelation of the solid skeletons, and stabilized with the help of surfactants and particles at the interfaces. The consolidated foams are afterwards heated at high temperatures to obtain porous ceramics. We describe below the foaming methods currently available on synthesis of porous UHTCs.

Li et al. [23] prepared $\mathrm{ZrC} / \mathrm{C}$ foams by direct foaming the mixtures of foamable phenolic resin and zirconia sol. Volatile pentane is used as foaming agent. The stabilization of the bubbles is mainly due to the thermal setting of phenolic resin. By pyrolyzing the foamed green body at $1600{ }^{\circ} \mathrm{C}$, highly porous $\mathrm{ZrC} / \mathrm{C}$ foam was prepared (Figs. 7(a) and 7(b)). The density and porosity of $\mathrm{ZrC} / \mathrm{C}$ foam were $0.16-0.19 \mathrm{~g} / \mathrm{cm}^{3}$ and

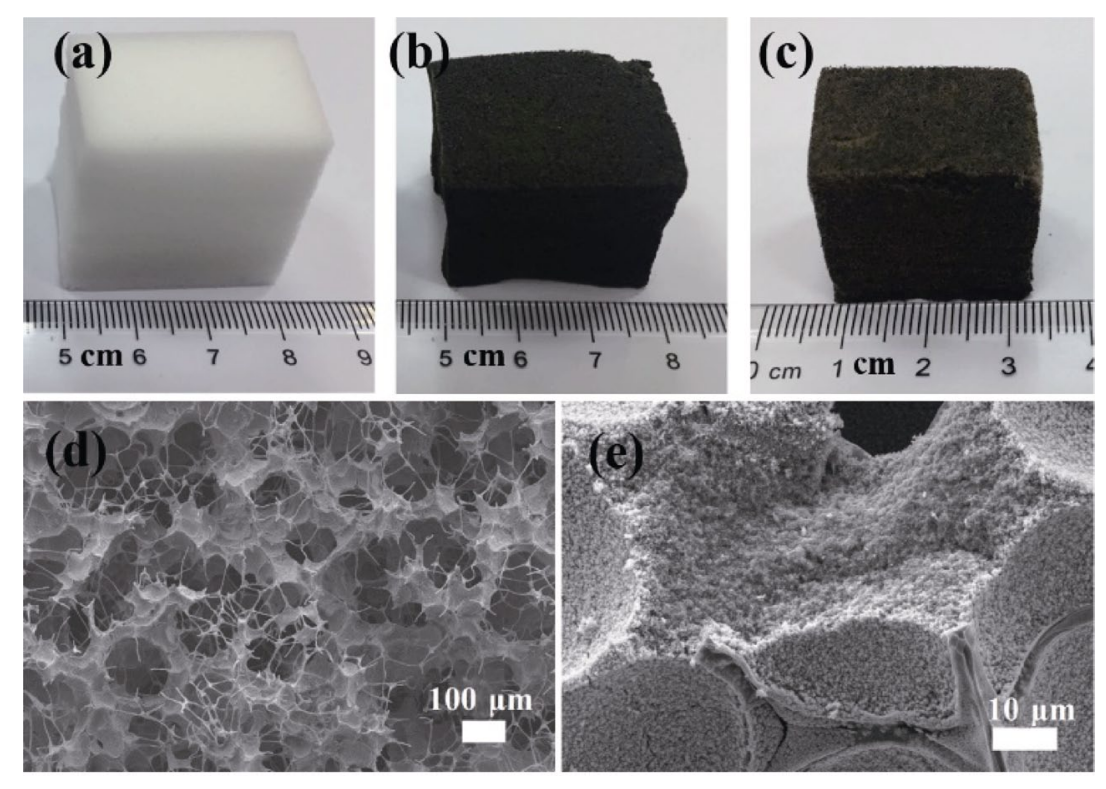

Fig. 6 (a) Photograph of one typical melamine foam. Photographs of the dried hybrid foams infiltrated with sols of (b) high viscosity and (c) low viscosity. (d) and (e) SEM images of the $1500{ }^{\circ} \mathrm{C}$-pyrolyzed foams impregnated with sols of viscosity 4.3 $\mathrm{cP}, 1500{ }^{\circ} \mathrm{C}$ in vacuum for $1 \mathrm{~h}$ [49]. Reproduced with permission from Ref. [49], (C) Springer Science+Business Media, LLC, part of Springer Nature 2018. 


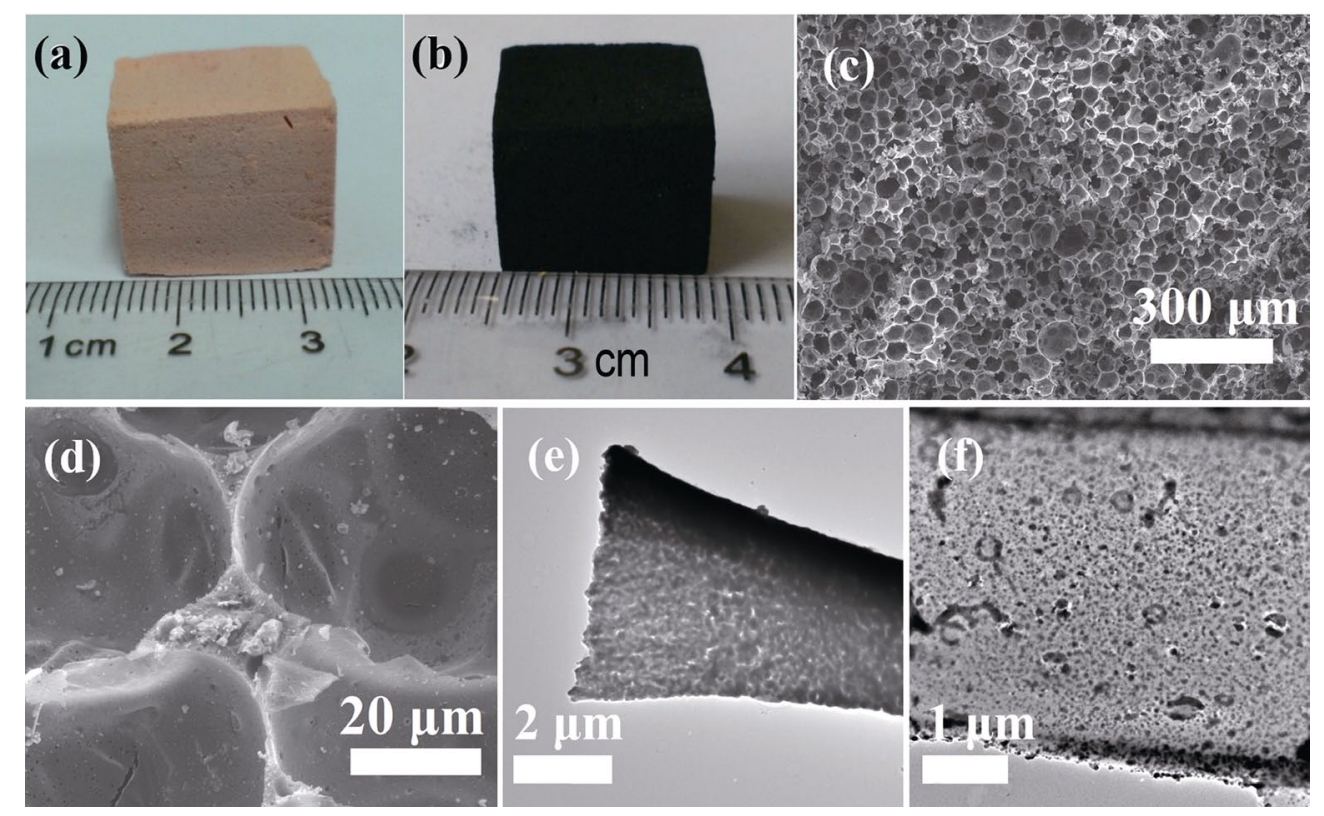

Fig. 7 (a) Photograph of the foamed green body and (b) $\mathrm{ZrC} / \mathrm{C}$ foam obtained from pyrolysis at $1600{ }^{\circ} \mathrm{C}$ for $1 \mathrm{~h}$. SEM images of $\mathrm{ZrC} / \mathrm{C}$ foam after pyrolysis at $1600{ }^{\circ} \mathrm{C}$ with (c) low and (d) high magnification. TEM images of (e) the strut and (f) cell wall of $\mathrm{ZrC} / \mathrm{C}$ foam after pyrolysis at $1600{ }^{\circ} \mathrm{C}$ [23]. Reproduced with permission from Ref. [23], CC Elsevier Ltd. 2014.

$83 \%-90 \%$, respectively. The as-prepared $\mathrm{ZrC}$ foam showed spherical closed cell structures with average cell sizes about $40 \mu \mathrm{m}$, as shown in Figs. 7(c) and 7(d). The foamability of the mixtures originated from phenolic resin and it decreased as the zirconia sol content increased. It is difficult to precisely control carbon residue in the phenolic resin foaming derived porous $\mathrm{ZrC} / \mathrm{C}$. In the cell walls, $\mathrm{ZrC}$ particles were embedded in the continuous carbon matrix, as shown in Figs. 7(e) and 7(f). Carbon residue might hinder the $\mathrm{ZrC}$ grain growth at high temperatures, which might be one of the reasons why these $\mathrm{ZrC} / \mathrm{C}$ foams displayed excellent thermal stability up to $2400{ }^{\circ} \mathrm{C}$.

$\mathrm{Li}$ et al. [25] developed a method to prepare stoichiometric $\mathrm{ZrC}$ foams by direct foaming of zirconia sols. Sucrose was used as carbon source and was dissolved into zirconia sol to get a viscous sol. The stabilization of the wet foam was based on the gelation of the zirconia sol under thermal aging. The microstructure of the $\mathrm{ZrC}$ foams can be tailored by controlling the foaming parameters, such as the viscosities of the sols, the concentration of the blowing and curing agents, which influenced the growth and stabilization of the bubbles in wet foam, as illustrated in Fig. 8. Pore sizes within the range of 40 to $500 \mu \mathrm{m}$ have been achieved using this zirconia sol foaming method. The densities of the stoichiometric $\mathrm{ZrC}$ foams were in the range of $0.12-0.53 \mathrm{~g} / \mathrm{cm}^{3}$.

\section{4 Solvent evaporation methods}

As described above, the sols are transformed into particulate gels that are established by van der Waals forces [46]. There are continuous liquid phase and solid phase in the wet gels. The solvent space between the solid network represents the potential pore space after drying [29,45]. In solvent evaporation methods, by forming a strengthened organic/inorganic interpenetrating network, the solvent is evaporated while the solid networks are preserved with limited shrinkage. By carbothermal conversion of interpenetrating metal oxide/resorcinol-formaldehyde (RF) nanoparticle networks, Leventis et al. [57] prepared monolithic HfC aerogels with diameter of $0.85 \mathrm{~cm}$. The polymerization of RF sols and gelation of hydrated $\mathrm{HfCl}_{4}$ with the help of epichlorohydrin occur in the same time scale, which leads to the formation of interpenetrating $\mathrm{HfO}_{x} / \mathrm{RF}$ nanoparticle networks. By critical fluid (SCF) $\mathrm{CO}_{2}$ drying of the wet gels followed with pyrolysis at $1400{ }^{\circ} \mathrm{C}$, HfC aerogels with porosity of $95 \%$ and average pore diameter of $22.9 \mathrm{~nm}$ are obtained. HfC xerogels with porosity of $44 \%$ and pore diameter of $3.1 \mathrm{~nm}$ are prepared by ambient pressure drying the wet gels. The morphologies of the HfC aerogels and xerogels are shown in Fig. 9.

To avoid cracking of the FA/zirconium oxychloride (ZOC)/TEOS hybrid gels during drying, Li et al. [21] 


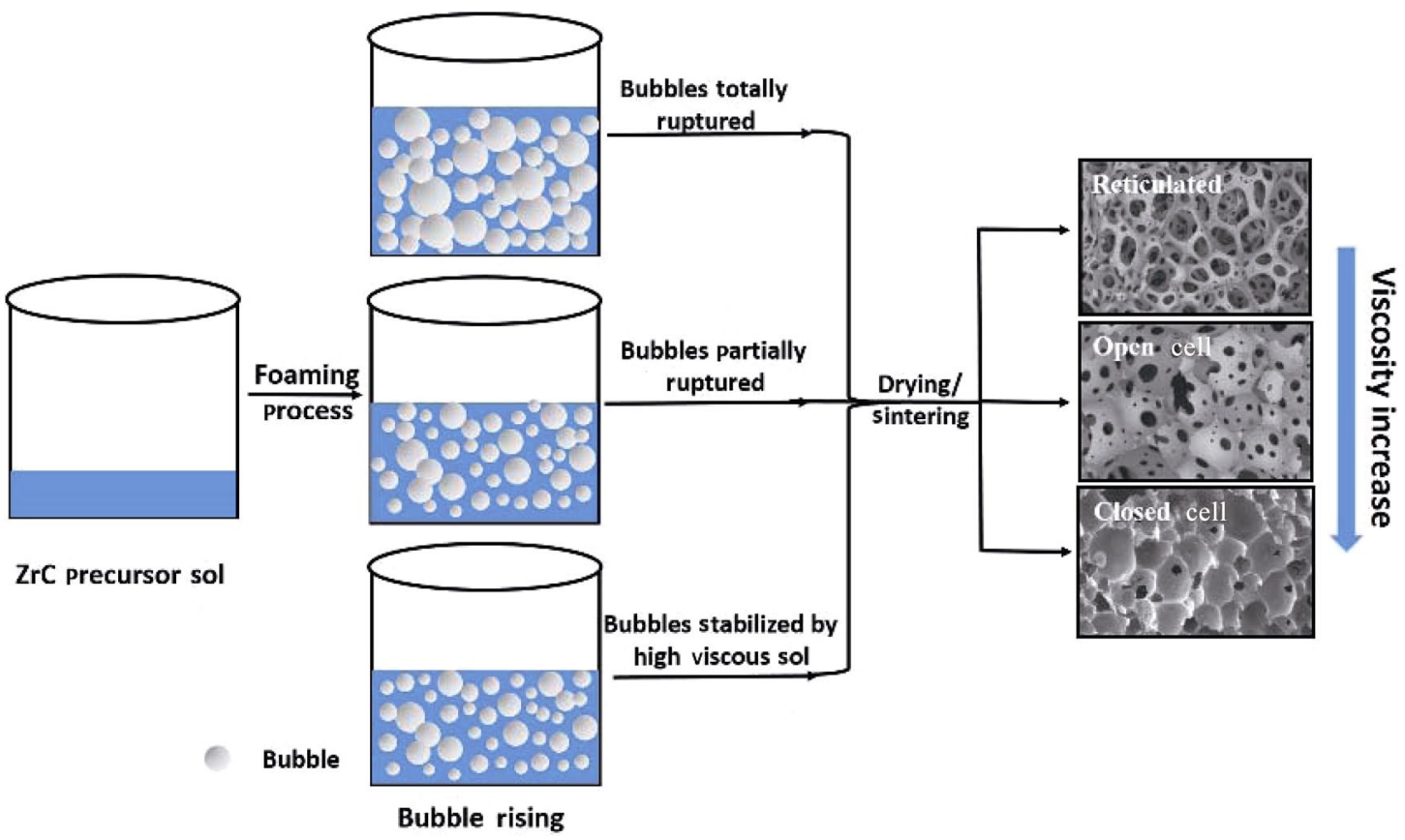

Fig. 8 Schematic illustration of the bubble growth and stabilization and the final microstructure of stoichiometric $\mathrm{ZrC}$ foams [25]. Reproduced with permission from Ref. [25], (c) Springer Science+Business Media New York 2015.

Native RF-HfO $x$

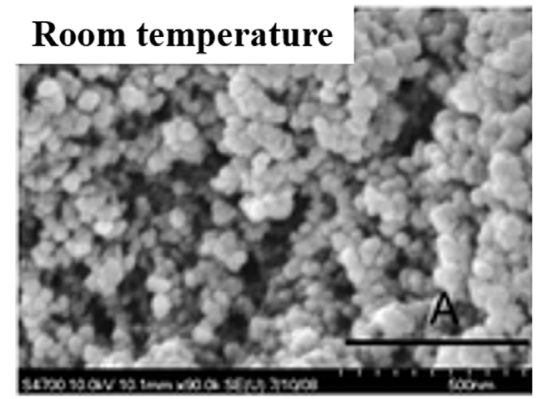

\section{X-RF-HfO $x$}

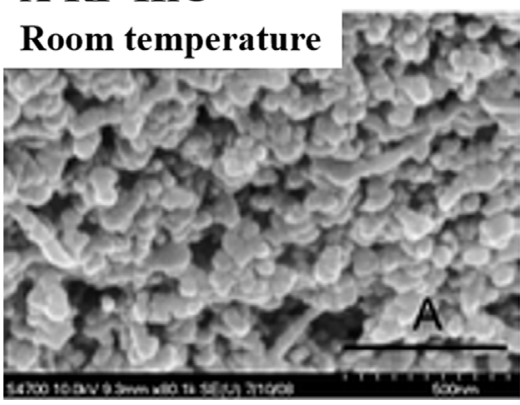

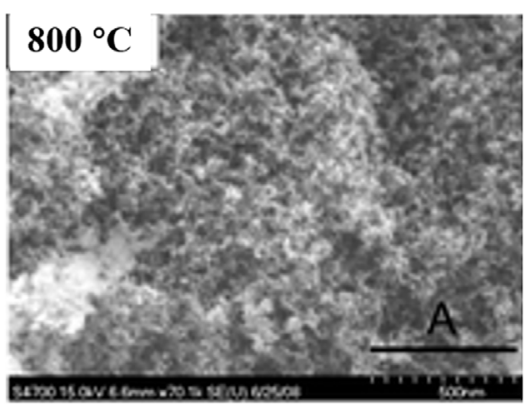
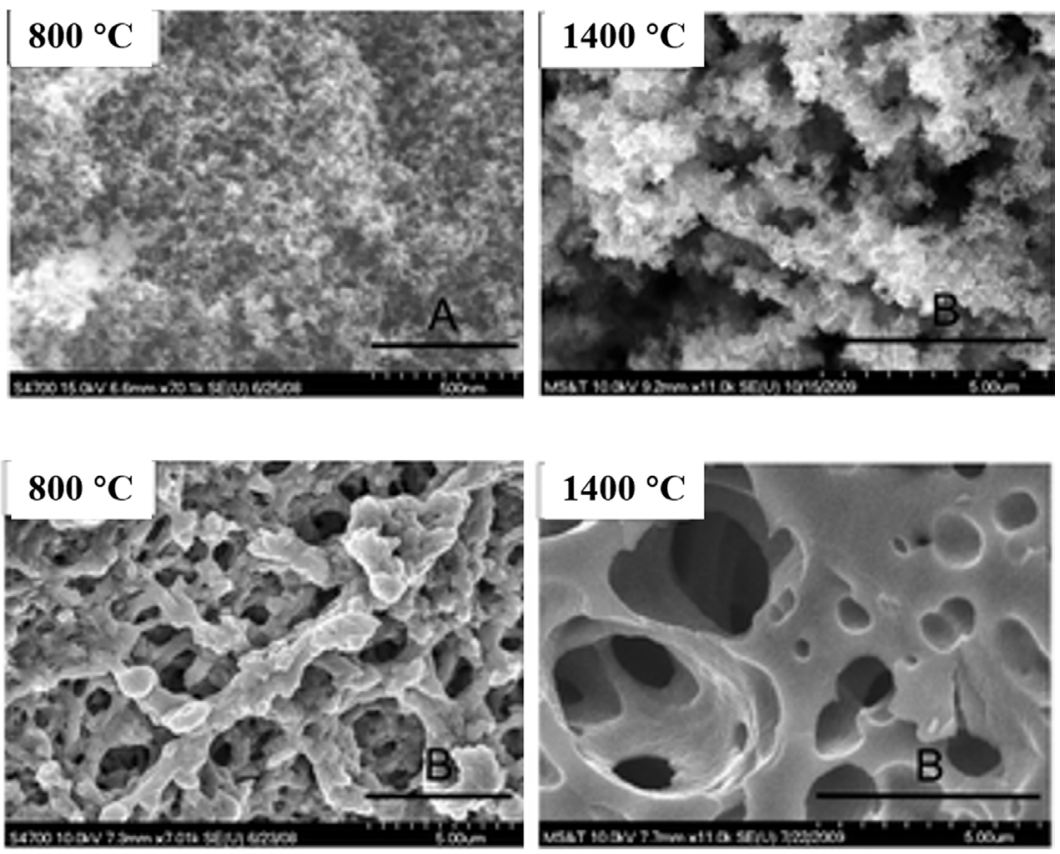

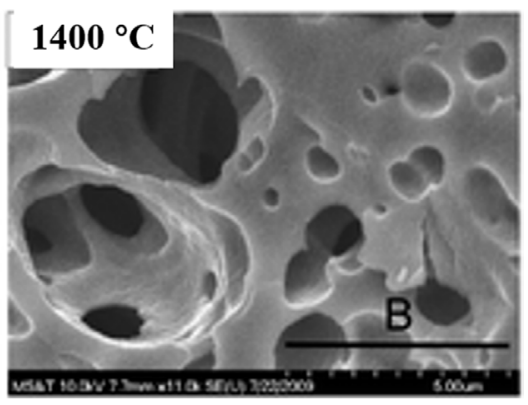

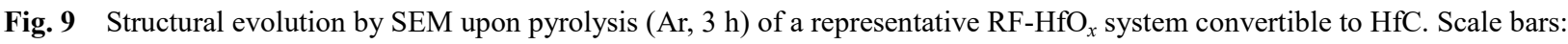
A, $500 \mathrm{~nm} ; \mathrm{B}, 5 \mu \mathrm{m}$ [26]. Reproduced with permission from Ref. [26], (C) Elsevier Ltd and Techna Group S.r.1. 2016.

used polyethylene glycol (PEG) as phase separation inducing agent to prepare porous $\mathrm{ZrC} / \mathrm{SiC}$ ceramics. PEG may strengthen the gel networks possibly by hydrogen bonding, and hence makes the porous networks robust enough to withstand the capillary forces during ambient pressure drying, as schematically illustrated in Fig. 10(a). Upon pyrolysis of the monolithic hybrid gels at temperatures above $1300{ }^{\circ} \mathrm{C}$, porous $\mathrm{ZrC} / \mathrm{SiC}$ ceramics with porosities around $70 \%$ could be obtained. Simply by adjusting the PEG concentration in the starting 


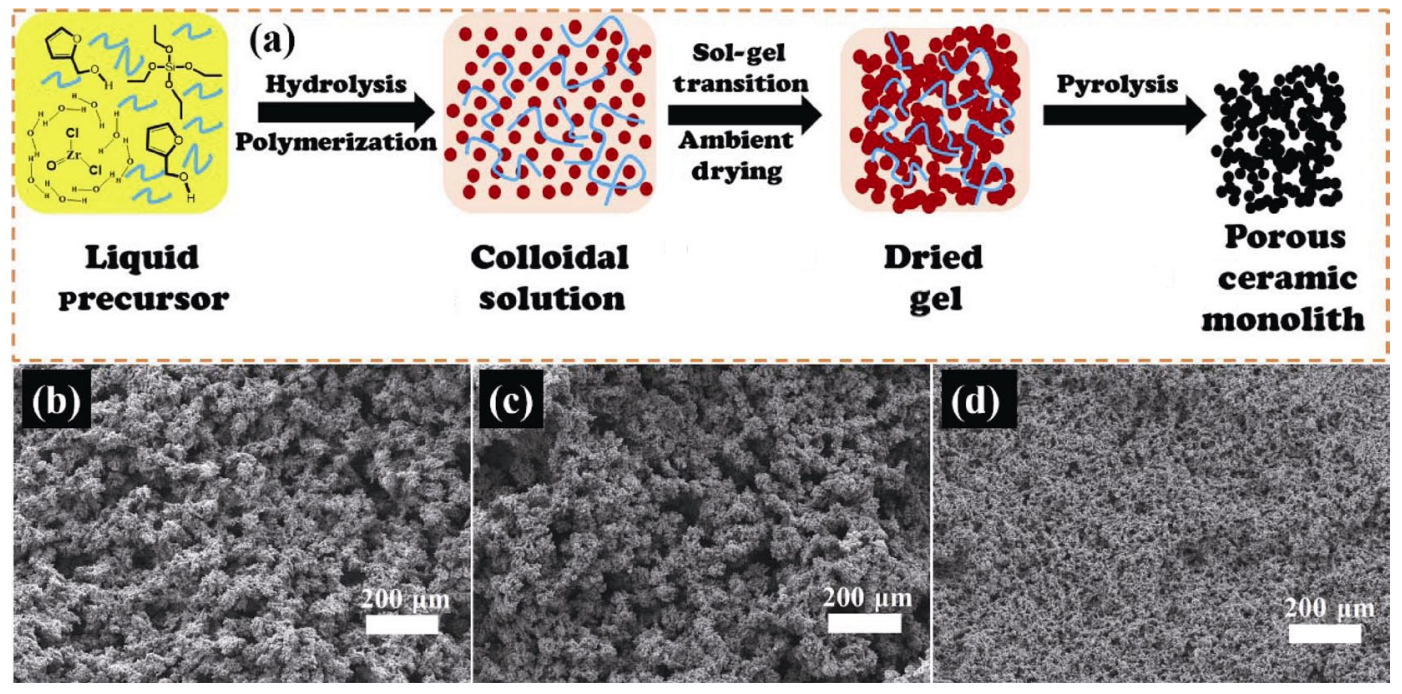

Fig. 10 (a) Schematic illustration for the preparation of porous $\mathrm{ZrC} / \mathrm{SiC}$ ceramics with $\mathrm{PEG}$ as additive. SEM images of the porous $\mathrm{ZrC} / \mathrm{SiC}$ ceramics with (b) low, (c) medium, and (d) high PEG concentration in the starting sol composition [21]. Reproduced with permission from Ref. [21], (c) Elsevier Ltd and Techna Group S.r.l. 2016.

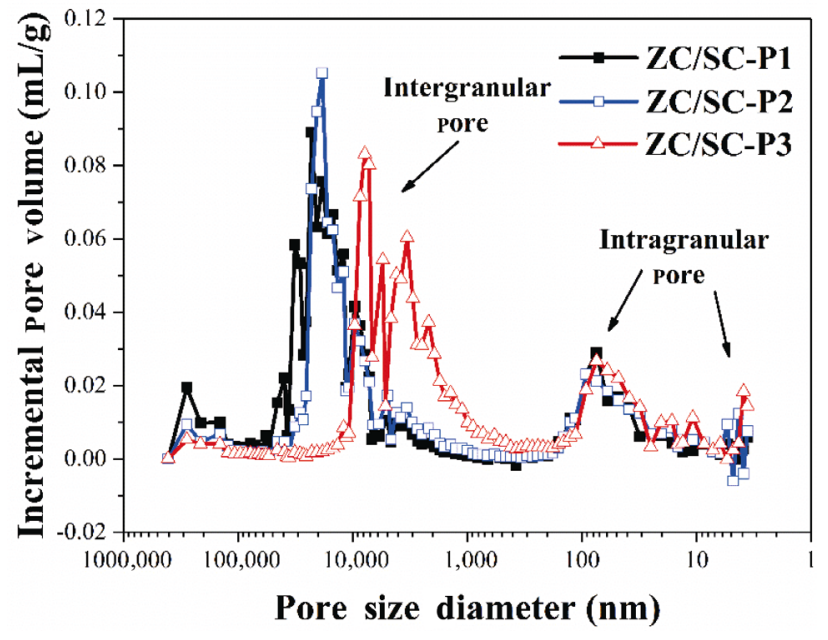

Fig. 11 Pore size distribution of the porous $\mathrm{ZrC} / \mathrm{SiC}$ ceramics via solvent evaporation methods [21]. Reproduced with permission from Ref. [21], (C) Elsevier Ltd and Techna Group S.r.1. 2016.

composition, the morphology, pore sizes and their distribution, and mechanical properties of the porous $\mathrm{ZrC} / \mathrm{SiC}$ can be tailored, as shown in Figs. 10(b), 10(c), and 11 . The as-prepared porous $\mathrm{ZrC} / \mathrm{SiC}$ ceramics are typical particulate gel structures and composed of spherical particles. These porous $\mathrm{ZrC} / \mathrm{SiC}$ ceramics possess multimodal pore size distribution, distribution peaks in micron-sized range associated with voids between large clusters, and distribution peaks in nano-sized range associated with the pores within the spherical particles, as depicted in Fig. 11.

In the case of synthesizing transition metal boride- based porous ceramics, Li et al. [22] used FA, zirconium $n$-butoxide (ZTB), and boric acid as carbon, zirconium, and boron sources, respectively. By combining acid-catalyzed polymerization of FA and gelation of inorganic components, porous hybrid monoliths can be obtained by direct drying the wet gels under ambient pressure. Figures 12(a) and 12(b) demonstrate that these hybrid monoliths possess quite uniform porous morphology and have monomodal pore size distribution in the range from 0.3 to $3 \mu \mathrm{m}$. The hybrid monoliths composed of interconnected colloidal particles, whose sizes decrease with the increase of FA/Zr molar ratio. The porous structures composed of particle chains and narrow pore size distribution are well retained after ceramization at temperatures up to 1300-1600 ${ }^{\circ} \mathrm{C}$, as shown in Figs. 12(c)-12(f). In the case of $\mathrm{FA} / \mathrm{Zr}$ equal to 3 , the particle chains become fibrillar and the ceramic product shows typical reticulated porous structures (Fig. 12(e)). The $\mathrm{ZrB}_{2}$-based porous ceramics via solvent evaporation method can reach porosity of $70 \%-85 \%$ and possess a monomodal pore size distribution between 1 and $10 \mu \mathrm{m}$.

\section{Properties of the sol-gel derived porous UHTCs}

Porous UHTCs are expected as promising candidate materials for the thermal protection systems of reusable launch and hypersonic vehicle [16,24]. These porous UHTCs must be lightweight and high temperature 

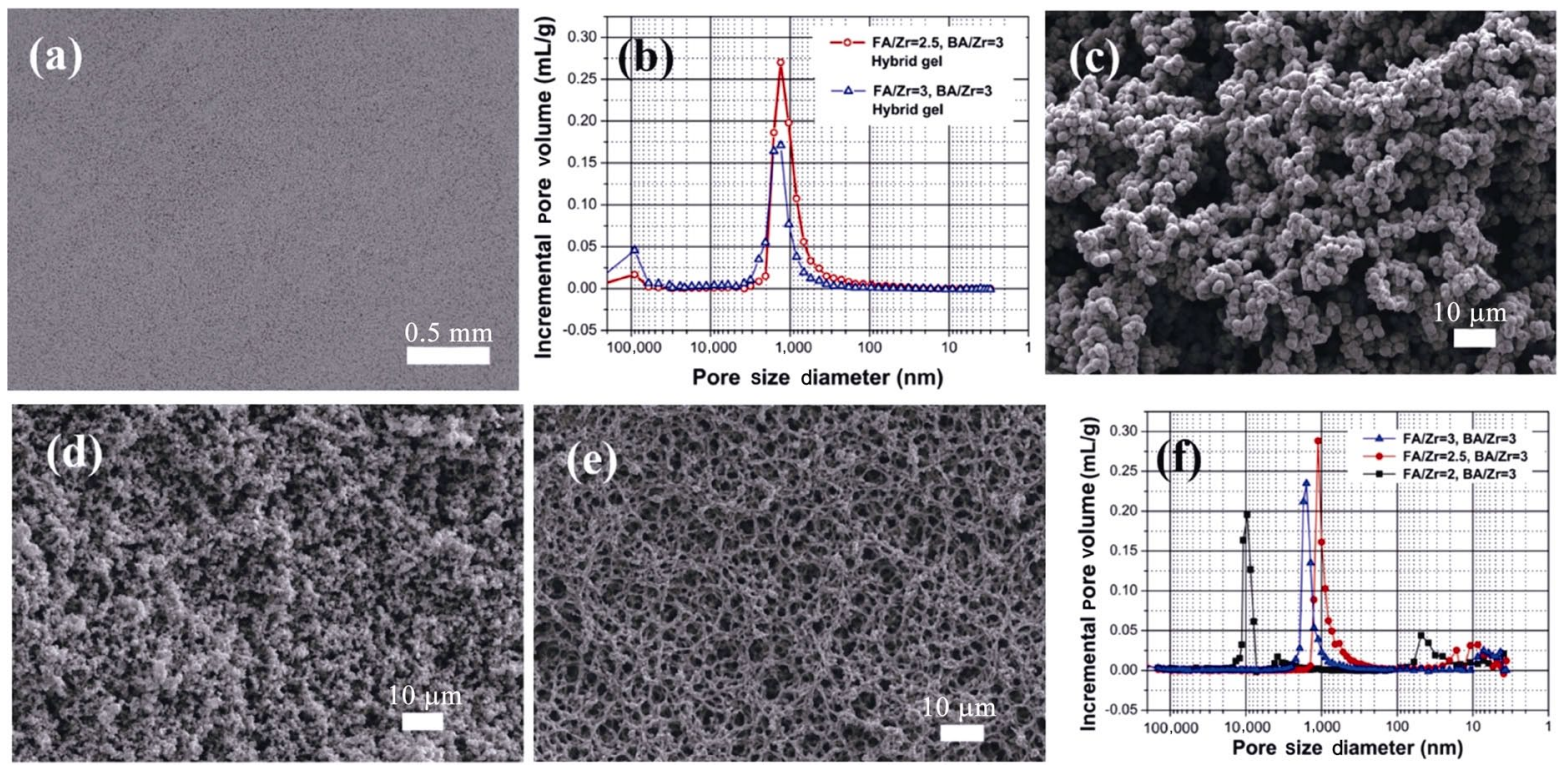

Fig. 12 (a) SEM image and (b) pore size distribution of the hybrid gels. SEM images and pore size distribution of the $\mathrm{ZrB}_{2}$-based porous ceramics with various $\mathrm{FA} / \mathrm{Zr}$ molar ratios: (c) $\mathrm{FA} / \mathrm{Zr}=2$, (d) $\mathrm{FA} / \mathrm{Zr}=2.5$, and (e) $\mathrm{FA} / \mathrm{Zr}=3$ [22]. Reproduced with permission from Ref. [22], (C) Elsevier Ltd. 2017.

resistant, have a suitable mechanical integrity, low thermal conductivity, and be able to accommodate a complex geometry during the integration. Generally, the properties of the solid of which the cellular ceramic is made, the topology and shape of the cells, and the relative density of the cellular ceramic are three dominate factors that influence cellular properties [15]. However, in terms of sol-gel derived porous UHTCs, the papers are very limited, and few preliminary studies on compressive strength, high temperature resistance, and thermal conductivity have been carried out. The amount of the tested specimens is too small, and it is difficult to give out an overall view of the properties of the sol-gel derived porous UHTCs. We describe some case studies below for the properties of these materials.

\section{1 Compressive strength}

Similar to many other porous oxide ceramics, the highly porous $\mathrm{ZrC}$ foams with spherical cell structures demonstrate huge strain before crushing, as depicted in Fig. 13(a) $[23,25,37]$. The stress-strain curve shows a linear elastic region followed by a plateau region, and ended with a densification region at large strain. Upon compression, the $\mathrm{ZrC}$ foam undergoes a progressive collapse of the cells and gives rise to the stress-strain plateau. Beyond the plateau, densification takes place and the stress rises sharply.

The stress-strain curves of the porous $\mathrm{ZrB}_{2}$-based ceramics with interstitial voids between skeletal particles display a brittle fracture behavior, indicating
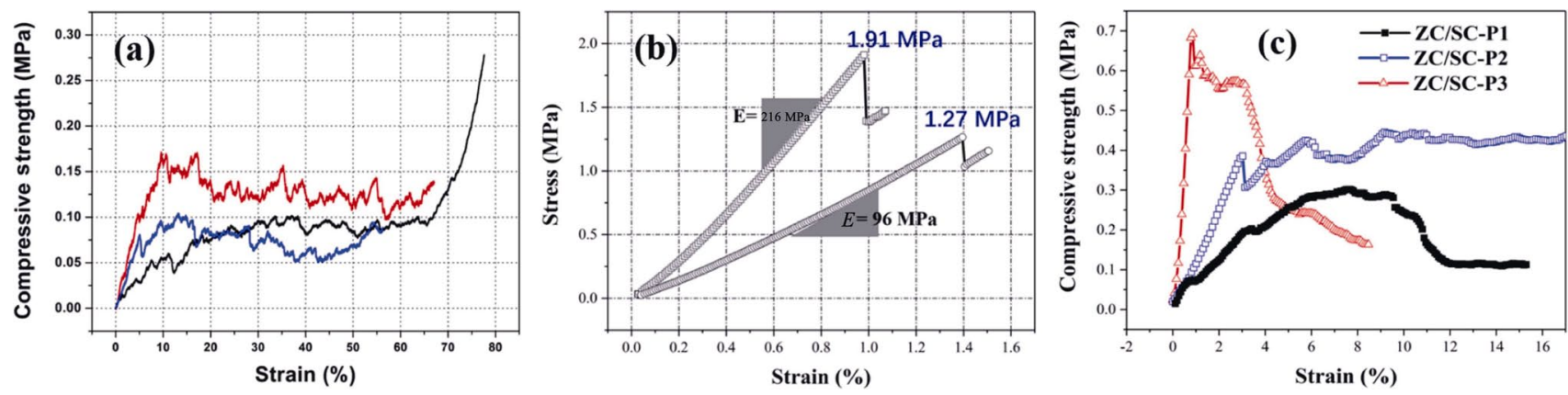

Fig. 13 Compressive stress-strain curves of the sol-gel derived porous UHTCs. (a) ZrC foams prepared by foaming method [37]. Reproduced with permission from Ref. [37], (C) IntechOpen 2019. (b) Porous $\mathrm{ZrB}_{2} / \mathrm{ZrC} / \mathrm{SiC}$ ceramics prepared by solvent evaporation method [22]. Reproduced with permission from Ref. [22], (C) Elsevier Ltd. 2017. (c) Porous $\mathrm{ZrC} / \mathrm{SiC}$ ceramics prepared by solvent evaporation method [21]. Reproduced with permission from Ref. [21], (C) Elsevier Ltd and Techna Group S.r.1. 2016. 
an elastic behavior up to a sudden rupture upon compression, as shown in Fig. 13(b) [22]. These rigid particle chains cannot withstand compressive loading through deformation, and hence display brittle fracture behavior upon external loading.

The compressive behavior of the sol-gel derived porous UHTCs demonstrates strong dependence on their microstructures (particle connectivity) [21]. Figure 13(c) shows the compressive stress-strain curves of the porous $\mathrm{ZrC} / \mathrm{SiC}$ via solvent evaporation method. The porous $\mathrm{ZrC} / \mathrm{SiC}$ ceramics composed of larger clusters of spherical particles which are less tightly connected have elastic and plateau region in their stress-strain curves. While those porous $\mathrm{ZrC} / \mathrm{SiC}$ ceramics composed of tightly bounded particles demonstrate brittle fracture behavior. These results confirm that the topology of the porous UHTCs are important factors and can be used to tailor their mechanical properties.

\section{2 High-temperature stability}

The difference in potential application temperature is one of the important features that distinguishes UHTCs from conventional ceramics. Porous UHTCs are expected to be used as thermal insulators at extreme high temperatures above $2000{ }^{\circ} \mathrm{C}$. The high temperature stability is one of the key properties to evaluate the overall performance of the porous UHTCs. Li et al. $[22,23]$ studied the high-temperature macroscopic dimensional and microstructure stability of the $\mathrm{ZrC} / \mathrm{C}$ foam and $\mathrm{ZrB}_{2}$-based porous ceramics by thermal aging these ceramics at temperatures from 2000 to $2400{ }^{\circ} \mathrm{C}$ in inert atmosphere. These sol-gel derived porous UHTCs are sintering resistant and possess excellent high-temperature stability. After aged at 2000-2400 ${ }^{\circ} \mathrm{C}$, no obvious geometric changes or structural damages are detected. The microstructures of the $\mathrm{ZrB}_{2}$-based porous ceramics are very stable and no coarse-grained morphology is observed after thermal aging at $2000{ }^{\circ} \mathrm{C}$ for $1 \mathrm{~h}$, as shown in Fig. 14. Carbon residue, which may hinder grain growth at hightemperature aging, might be one of the key factors that give rise to high-temperature stability of these porous UHTCs.

\section{3 Thermal conductivity}

Few papers reported the thermal properties of the sol-gel derived porous UHTCs. Li et al. [23] measured the thermal conductivity of the closed cell $\mathrm{ZrC} / \mathrm{C}$ foam with porosity of $85 \%$ and the average pore size of $40 \mu \mathrm{m}$, as depicted in Fig. 15. Its thermal conductivity at $50{ }^{\circ} \mathrm{C}$ is $0.96 \mathrm{~W} /(\mathrm{m} \cdot \mathrm{K})$ and increases rapidly in the temperature from 50 to $200{ }^{\circ} \mathrm{C}$, and then reaches a plateau at $300{ }^{\circ} \mathrm{C}$ with thermal conductivity of $1.36 \mathrm{~W} /(\mathrm{m} \cdot \mathrm{K})$. A combined thermal conductivity of around $5 \mathrm{~W} /(\mathrm{m} \cdot \mathrm{K})$ is generally recommended for aerospace applications $[16,63]$. This closed cell $\mathrm{ZrC} / \mathrm{C}$ foam is promising candidate material for aerospace with excellent high-temperature resistance.

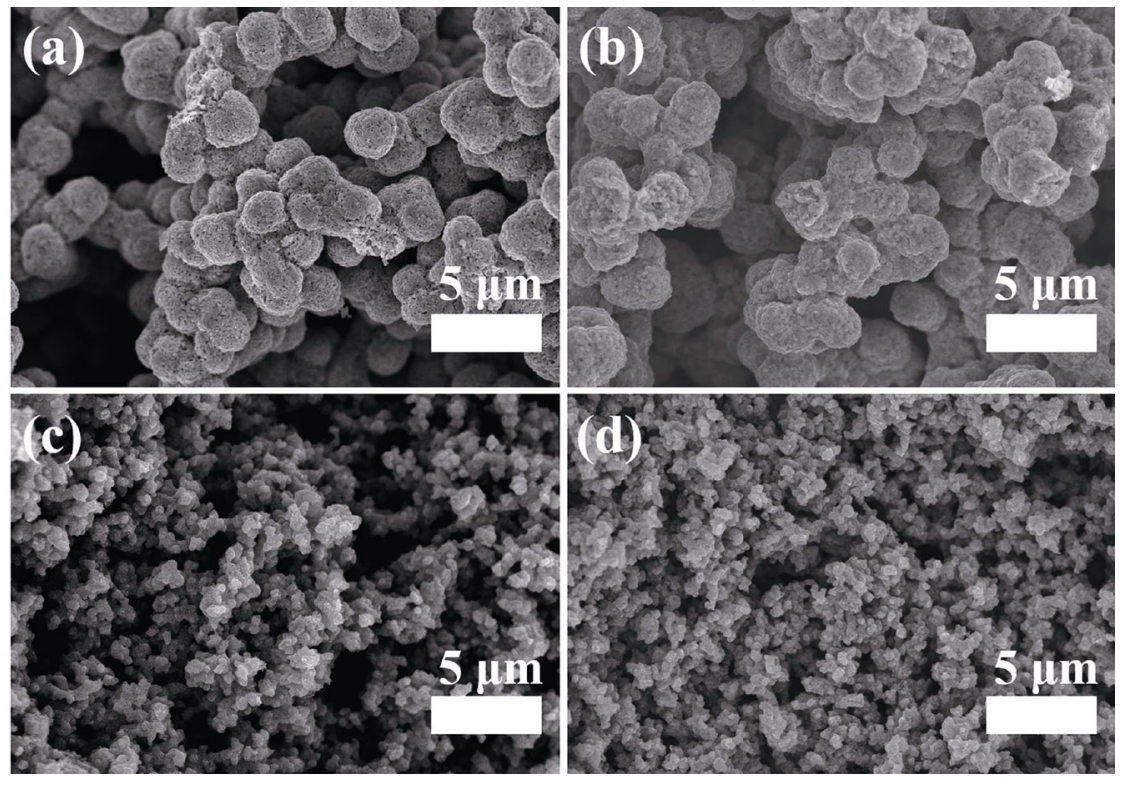

Fig. $14 \mathrm{SEM}$ images of the porous $\mathrm{ZrB}_{2} / \mathrm{ZrC} / \mathrm{SiC}$ ceramics via solvent evaporation method before and after thermal aging at $2000{ }^{\circ} \mathrm{C}$ for $1 \mathrm{~h}$ [22]. Reproduced with permission from Ref. [22], C Elsevier Ltd. 2017. 


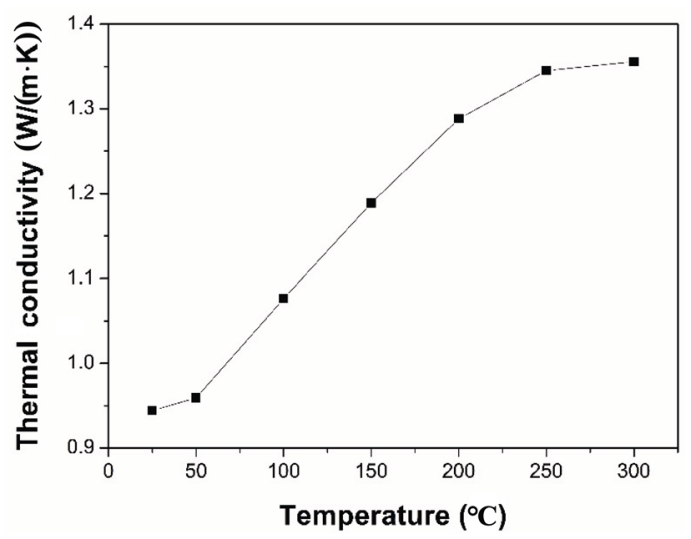

Fig. 15 Temperature dependence of thermal conductivity of the closed cell $\mathrm{ZrC} / \mathrm{C}$ foams prepared by foaming methods [23]. Reproduced with permission from Ref. [23], (C) Elsevier Ltd. 2014.

\section{Summary and outlook}

Several sol-gel based processing routes using templating, foaming, and solvent evaporation are nowadays available for the production of porous UHTCs. The sol-gel methods for porous UHTCs involve the synthesis of liquid precursors, shaping the precursors to get green body, and heating at high temperatures to complete the ceramization. The key for all of these synthetic methods is pore designing.

In templating methods, the porous structure originates from the porous template. It is possible to produce a wide variety of porous UHTCs by this templating method. By impregnating/infiltrating the liquid precursors, followed by drying, and pyrolysis at $1300-1600{ }^{\circ} \mathrm{C}$, the porous UHTCs with pore sizes ranging from 10 to $200 \mu \mathrm{m}$ at porosity levels of $80 \%$ can be produced. The rheology of the impregnating sol and its adhesion on the template are key issues in templating methods. It is important to keep in mind that high residue carbon content can be introduced into the final porous UHTCs if wood-derived carbon is chosen as the template.

In foaming methods, the porous structure originates from the generation and stabilization of the gas bubbles. By introducing the gas bubbles or volatile chemicals to the sol, followed by thermal setting or gelation of the sol, and heating at $1500-1600{ }^{\circ} \mathrm{C}$, the porous UHTCs with typical spherical cell structures of porosity ranging from $60 \%$ to $95 \%$ and cell sizes varying from 40 to $500 \mu \mathrm{m}$ can be obtained. The open cell and closed cell structures of the porous UHTCs can be tailored by balancing the bubble growth and stabilization.

In solvent evaporation methods, the pores are generated by evaporating the solvent between the solid network. The key issue in these methods is how to avoid cracking and large volume shrinkage during drying. Supercritical fluid drying, surface modification, and the formation of interpenetrated particle networks have been used to weaken the capillary forces during drying process to obtain monolithic samples. By supercritical fluid drying the wet gel followed with high-temperature pyrolysis, HfC aerogels with average pore sizes of $22.9 \mathrm{~nm}$ and porosities over $95 \%$ can be obtained. Porous UHTCs with pore sizes ranging from 1 to $20 \mu \mathrm{m}$ and porosities ranging from $65 \%$ to $85 \%$ can be produced by carbothermal conversion of the ambient pressure dried interpenetrated particles networks.

Application oriented studies of the sol-gel derived porous UHTCs are very limited. Porous UHTCs may be considered as good candidates for thermal protection systems used in extreme high temperatures. Sol-gel derived porous UHTCs demonstrate excellent high temperature stability and are sintering resistant at temperatures up to $2000-2400{ }^{\circ} \mathrm{C}$. The compressive strength of the porous UHTCs can reach up to $1.9 \mathrm{MPa}$ with porosities over $80 \%$. Thermal conductivity of the $\mathrm{ZrC} / \mathrm{C}$ foam is about $1 \mathrm{~W} /(\mathrm{m} \cdot \mathrm{K})$ at $25{ }^{\circ} \mathrm{C}$ and increases with the increasing temperature. The preliminary studies of the properties of these sol-gel derived porous UHTCs show that they are promising materials for extreme high temperature applications, such as thermal protection systems of reusable launch and hypersonic vehicles. However, systematical studies to characterize the mechanical, thermal conductivity, thermal shock resistance, and thermal expansion properties of these porous UHTCs are needed.

Due to limited researches in sol-gel derived porous UHTCs, a detailed study to reveal the processingstructure-property relations for each of the main processing routes is still required. We hope that more progress will be made in the future by excellent research contributions. The systematical study would lead to significant advance not only in the precursor synthesis area, but also on the preparation of ultra-high temperature ceramic matrix composites for extreme applications.

\section{Acknowledgements}

Financial support from the National Natural Science 
Foundation of China (Nos. 51602324 and 51532009) and the Fundamental Research Funds for the Central Universities (No. 2232018D3-32) are gratefully acknowledged.

\section{References}

[1] Zhang GJ, Ni DW, Zou J, et al. Inherent anisotropy in transition metal diborides and microstructure/property tailoring in ultra-high temperature ceramics-A review. $J$ Eur Ceram Soc 2018, 38: 371-389.

[2] Bao WC, Robertson S, Liu JX, et al. Structural integrity and characteristics at lattice and nanometre levels of $\mathrm{ZrN}$ polycrystalline irradiated by $4 \mathrm{MeV}$ Au ions. J Eur Ceram Soc 2018, 38: 4373-4383.

[3] $\mathrm{Lu} \mathrm{Y,} \mathrm{Zou} \mathrm{J,} \mathrm{Xu} \mathrm{FF,} \mathrm{et} \mathrm{al.} \mathrm{Volatility} \mathrm{diagram} \mathrm{of}$ $\mathrm{ZrB}_{2}-\mathrm{SiC}-\mathrm{ZrC}$ system and experimental validation. $J \mathrm{Am}$ Ceram Soc 2018, 101: 3627-3635.

[4] Ji Z, Rubio V, Binner J. Thermoablative resistance of $\mathrm{ZrB}_{2}$-SiC-WC ceramics at $2400{ }^{\circ} \mathrm{C}$. Acta Mater 2017, 133: 293-302.

[5] Zhang GJ, Deng ZY, Kondo N, et al. Reactive hot pressing of $\mathrm{ZrB}_{2}-\mathrm{SiC}$ composites. J Am Ceram Soc 2004, 83: 2330-2332.

[6] Fahrenholtz WG, Hilmas GE. Ultra-high temperature ceramics: Materials for extreme environments. Scr Mater 2017, 129: 94-99.

[7] Wuchina E, Opeka M, Causey S, et al. Designing for ultrahigh-temperature applications: The mechanical and thermal properties of $\mathrm{HfB}_{2}, \mathrm{HfC}_{x}, \mathrm{HfN}_{x}$ and $\alpha \mathrm{Hf}(\mathrm{N}) . J$ Mater Sci 2004, 39: 5939-5949.

[8] Opeka MM, Talmy IG, Wuchina EJ, et al. Mechanical, thermal, and oxidation properties of refractory hafnium and zirconium compounds. J Eur Ceram Soc 1999, 19: 24052414.

[9] Paul A, Jayaseelan DD, Venugopal S, et al. UHTC composites for hypersonic applications. American Ceramic Society Bulletin 2012, 91: 22-29.

[10] Justin JF, Jankowiak A. Ultra high temperature ceramics: densification, properties and thermal stability. Aerosp $J$ 2011: 1-11.

[11] Krishnarao RV, Bhanuprasad VV, Madhusudhan Reddy G. $\mathrm{ZrB}_{2}-\mathrm{SiC}$ based composites for thermal protection by reaction sintering of $\mathrm{ZrO}_{2}+\mathrm{B}_{4} \mathrm{C}+\mathrm{Si}$. $J$ Adv Ceram 2017, 6: 320-329.

[12] Gui KX, Liu FY, Wang G, et al. Microstructural evolution and performance of carbon fiber-toughened $\mathrm{ZrB}_{2}$ ceramics with $\mathrm{SiC}$ or $\mathrm{ZrSi}_{2}$ additive. $J$ Adv Ceram 2018, 7: 343-351.

[13] He RJ, Qu ZL, Liang D. Rapid heating thermal shock study of ultra high temperature ceramics using an in situ testing method. J Adv Ceram 2017, 6: 279-287.

[14] Fahrenholtz WG, Wuchina EJ, Lee WE, et al. Ultra-high Temperature Ceramics: Materials for Extreme Environment Applications. Hoboken (USA): John Wiley \& Sons, Inc., 2014.
[15] Scheffler M, Colombo P. Cellular Ceramics: Structure, Manufacturing, Properties and Applications. New York: Wiley-VCH Verlag GmbH \& Co. KGaA, 2005.

[16] Tallon C, Franks GV. Multi-scale porous ultra-high temperature ceramics. Final project report. Sponsored by Asian Office of Aerospace Research and Development. Grant Number: AOARD-134068. 2015: 43.

[17] Du JC, Zhang XH, Hong CQ, et al. Microstructure and mechanical properties of $\mathrm{ZrB}_{2}-\mathrm{SiC}$ porous ceramic by camphene-based freeze casting. Ceram Int 2013, 39: 953-957.

[18] Landi E, Sciti D, Melandri C, et al. Ice templating of $\mathrm{ZrB}_{2}$ porous architectures. J Eur Ceram Soc 2013, 33: 15991607.

[19] Sani E, Mercatelli L, Sans JL, et al. Porous and dense hafnium and zirconium ultra-high temperature ceramics for solar receivers. Opt Mater 2013, 36: 163-168.

[20] Jin XX, Dong LM, Li Q, et al. Thermal shock cracking of porous $\mathrm{ZrB}_{2}-\mathrm{SiC}$ ceramics. Ceram Int 2016, 42: 13309 13313.

[21] Li F, Wang XG, Huang X, et al. Preparation of $\mathrm{ZrC} / \mathrm{SiC}$ porous self-supporting monoliths via sol-gel process using polyethylene glycol as phase separation inducer. $J$ Eur Ceram Soc 2018, 38: 4806-4813.

[22] Li F, Huang X. Preparation of highly porous $\mathrm{ZrB}_{2} / \mathrm{ZrC} / \mathrm{SiC}$ composite monoliths using liquid precursors via direct drying process. J Eur Ceram Soc 2018, 38: 1103-1111.

[23] Li F, Kang Z, Huang X, et al. Preparation of zirconium carbide foam by direct foaming method. J Eur Ceram Soc 2014, 34: 3513-3520.

[24] Fahrenholtz WG, Hilmas GE. Ultra-high temperature ceramics: Materials for extreme environments. Scr Mater 2017, 129: 94-99.

[25] Li F, Liang MS, Ma XF, et al. Preparation and characterization of stoichiometric zirconium carbide foams by direct foaming of zirconia sols. J Porous Mater 2015, 22: 493-500.

[26] Jin XX, Dong LM, Xu HY, et al. Effects of porosity and pore size on mechanical and thermal properties as well as thermal shock fracture resistance of porous $\mathrm{ZrB}_{2}-\mathrm{SiC}$ ceramics. Ceram Int 2016, 42: 9051-9057.

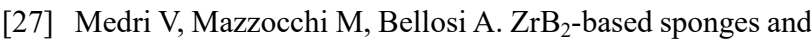
lightweight devices. Int J Appl Ceram Technol 2011, 8: 815-823.

[28] Franks GV, Tallon C, Studart AR, et al. Colloidal processing: Enabling complex shaped ceramics with unique multiscale structures. J Am Ceram Soc 2017, 100: 458-490.

[29] Feinle A, Elsaesser MS, Hüsing N. Sol-gel synthesis of monolithic materials with hierarchical porosity. Chem Soc Rev 2016, 45: 3377-3399.

[30] Okada K, Isobe T, Katsumata KI, et al. Porous ceramics mimicking nature-Preparation and properties of microstructures with unidirectionally oriented pores. Sci Technol Adv Mater 2011, 12: 064701. 
[31] Studart AR, Gonzenbach UT, Tervoort E, et al. Processing routes to macroporous ceramics: A review. $\mathrm{J} \mathrm{Am} \mathrm{Ceram}$ Soc 2006, 89: 1771-1789.

[32] Colombo P. In praise of pores. Science 2008, 322: 381-383.

[33] Qian YB, Zhang WG, Ge M, et al. Frictional response of a novel $\mathrm{C} / \mathrm{C}-\mathrm{ZrB}_{2}-\mathrm{ZrC}-\mathrm{SiC}$ composite under simulated braking. J Adv Ceram 2013, 2: 157-161.

[34] Guo XZ, Cai XB, Zhu L, et al. Preparation and properties of $\mathrm{SiC}$ honeycomb ceramics by pressureless sintering technology. J Adv Ceram 2014, 3: 83-88.

[35] Wu JM, Zhang XY, Xu J, et al. Preparation of porous $\mathrm{Si}_{3} \mathrm{~N}_{4}$ ceramics via tailoring solid loading of $\mathrm{Si}_{3} \mathrm{~N}_{4}$ slurry and $\mathrm{Si}_{3} \mathrm{~N}_{4}$ poly-hollow microsphere content. $J$ Adv Ceram 2015, 4: 260-266.

[36] Wu HB, Yin J, Liu XJ, et al. Aqueous gelcasting and pressureless sintering of zirconium diboride foams. Ceram Int 2014, 40: 6325-6330.

[37] Li F, Huang X, Zhang GJ. Preparation of ultra-high temperature ceramics-based materials by sol-gel routes. In Recent Applications in Sol-gel Synthesis. Usha C, Ed. InTech, 2017.

[38] Danks AE, Hall SR, Schnepp Z. The evolution of 'sol-gel' chemistry as a technique for materials synthesis. Mater Horiz 2016, 3: 91-112.

[39] Nakanishi K, Kanamori K, Tokudome Y, et al. Sol-gel processing of porous materials. In Handbook of Solid State Chemistry. Dronskowshi R, Kikkawa S, Stein A, Eds. New York: Wiley-VCH Verlag GmbH \& Co. KGaA, 2017.

[40] Sacks MD, Wang CA, Yang ZH, et al. Carbothermal reduction synthesis of nanocrystalline zirconium carbide and hafnium carbide powders using solution-derived precursors. J Mater Sci 2004, 39: 6057-6066.

[41] Dollé M, Gosset D, Bogicevic C, et al. Synthesis of nanosized zirconium carbide by a sol-gel route. J Eur Ceram Soc 2007, 27: 2061-2067.

[42] Yan CL, Liu RJ, Cao YB, et al. Carbothermal synthesis of submicrometer zirconium carbide from polyzirconoxane and phenolic resin by the facile one-pot reaction. $J \mathrm{Am}$ Ceram Soc 2012, 95: 3366-3369.

[43] Ang CE, Williams T, Seeber A, et al. Synthesis and evolution of zirconium carbide via sol-gel route: Features of nanoparticle oxide-carbon reactions. J Am Ceram Soc 2013, 96: 1099-1106.

[44] Cai T, Qiu WF, Liu D, et al. Synthesis of $\mathrm{ZrC}-\mathrm{SiC}$ powders by a preceramic solution route. $J$ Am Ceram Soc 2013, 96: 3023-3026.

[45] Ziegler C, Wolf A, Liu W, et al. Modern inorganic aerogels. Angew Chem Int Ed 2017, 56: 13200-13221.

[46] Brinker CJ, Scherer GW. Sol-Gel Science: The Physics and Chemistry of Sol-Gel Processing. San Diego (USA): Academic Press Inc., 1990.

[47] Ji ZH, Ye L, Tao XY, et al. Synthesis of ordered mesoporous $\mathrm{ZrC} / \mathrm{C}$ nanocomposite via magnesiothermic reduction at low temperature. Mater Lett 2012, 71: 88-90.

[48] Brinker CJ, Scherer GW. Drying. In Sol-Gel Science.
Brinker CJ, Scherer GW, Eds. San Diego (USA): Academic Press, 1990: 452-513.

[49] Li F, Bao WC, Ni DW, et al. A thermoset hybrid sol for the syntheses of zirconium carbide-silicon carbide foam via replica method. J Porous Mater 2019, 26: 409-417.

[50] Nakanishi K, Tanaka N. Sol-gel with phase separation. Hierarchically porous materials optimized for highperformance liquid chromatography separations. Acc Chem Res 2007, 40: 863-873.

[51] Basnet B, Sarkar N, Park JG, et al. $\mathrm{Al}_{2} \mathrm{O}_{3}-\mathrm{TiO}_{2} / \mathrm{ZrO}_{2}-\mathrm{SiO}_{2}$ based porous ceramics from particle-stabilized wet foam. $J$ Adv Ceram 2017, 6: 129-138.

[52] Krivoshapkina EF, Krivoshapkin PV, Vedyagin AA. Synthesis of $\mathrm{Al}_{2} \mathrm{O}_{3}-\mathrm{SiO}_{2}-\mathrm{MgO}$ ceramics with hierarchical porous structure. J Adv Ceram 2017, 6: 11-19.

[53] Rambo CR, Cao J, Rusina O, et al. Manufacturing of biomorphic ( $\mathrm{Si}, \mathrm{Ti}, \mathrm{Zr}$ )-carbide ceramics by sol-gel processing. Carbon 2005, 43: 1174-1183.

[54] Venugopal S, Boakye EE, Paul A, et al. Sol-gel synthesis and formation mechanism of ultrahigh temperature ceramic: $\mathrm{HfB}_{2}$. J Am Ceram Soc 2014, 97: 92-99.

[55] Tao XY, Qiu WF, Li H, et al. Synthesis of nanosized zirconium carbide from preceramic polymers by the facile one-pot reaction. Polym Adv Technol 2010, 21: 300-304.

[56] Li F, Huang X, Zhang GJ. Scalable foaming assisted synthesis of $\mathrm{ZrC}$ nanopowder by carbothermal reduction. Ceram Int 2015, 41: 3335-3338.

[57] Leventis N, Chandrasekaran N, Sadekar AG, et al. The effect of compactness on the carbothermal conversion of interpenetrating metal oxide/resorcinol-formaldehyde nanoparticle networks to porous metals and carbides. $J$ Mater Chem 2010, 20: 7456-7471.

[58] Jin XX, Zhang XH, Han JC, et al. Thermal shock behavior of porous $\mathrm{ZrB}_{2}-\mathrm{SiC}$ ceramics. Mater Sci Eng 2013, 588: $175-180$.

[59] Schwartzwalder K, Somers H, Somers AV. Method of making porous ceramic articles. U.S. patent 3090 094, May 1963.

[60] Gonzenbach UT, Studart AR, Tervoort E, et al. Ultrastable particle-stabilized foams. Angew Chem Int Ed 2006, 45: 3526-3530.

[61] Gonzenbach UT, Studart AR, Tervoort E, et al. Tailoring the microstructure of particle-stabilized wet foams. Langmuir 2007, 23: 1025-1032.

[62] Gonzenbach UT, Studart AR, Tervoort E, et al. Stabilization of foams with inorganic colloidal particles. Langmuir 2006, 22: 10983-10988.

[63] Zhang S, Zhao DL. Aerospace Materials Handbook. Boca Raton (USA): CRC Press, 2012.

Open Access This article is licensed under a Creative Commons Attribution 4.0 International License, which permits use, sharing, adaptation, distribution and reproduction in any medium or format, as long as you give appropriate credit to the original author(s) and the source, provide a link to the Creative 
Commons licence, and indicate if changes were made.

The images or other third party material in this article are included in the article's Creative Commons licence, unless indicated otherwise in a credit line to the material. If material is not included in the article's Creative Commons licence and your intended use is not permitted by statutory regulation or exceeds the permitted use, you will need to obtain permission directly from the copyright holder.

To view a copy of this licence, visit http://creativecommons. org/licenses/by/4.0/. 